\title{
Allocation of Expenditures in Elderly Households and the Cost of Widowhood ${ }^{a}$
}

\author{
Daniel Burkhard ${ }^{\mathrm{b}}$
}

JEL-Classification: D12, D13, C30

Keywords: Collective household model, indifference scale, resource shares, economies of scale in consumption, Engel curves, elderly households

\section{SUMMARY}

Widowhood and retirement change the economic environment of elderly households. While retirement changes income and expenditure patterns, widowhood fundamentally changes the structure of the household. Besides high non-monetary cost of losing the partner, resources are no longer shared and economies of scale arising from joint consumption are lost. This paper applies a collective household model to expenditure data on elderly households in Switzerland. The findings suggest that $44 \%$ of household resources are assigned to wives and both spouses save roughly $27 \%$ or, on average, 800 Swiss Francs on monthly expenditures relative to living apart. Estimates of indifference scales indicate that men suffer a financial loss after losing their wife, while widowed women do not.

a I am grateful to two anonymous referees, Aline Bütikofer, Michael Gerfin, Boris Kaiser, Kaspar Wüthrich, and seminar participants at the University of Bern for helpful suggestions and comments. All errors are my own. Financial support from the Swiss National Science Foundation (Grant 100018135379) is gratefully acknowledged.

b Department of Economics, University of Bern, Schanzeneckstrasse 1, CH-3001 Bern, Switzerland, daniel.burkhard@vwi.unibe.ch and CONCORDIA Versicherungen AG, Bundesplatz 15, CH-6002 Lucerne, Switzerland, daniel.burkhard@concordia.ch. The views expressed do not necessarily reflect those of CONCORDIA Versicherungen AG. 


\section{Introduction}

The elderly face specific economic conditions because they are at the age of transition to retirement. This is likely to change the economic environment of households and thereby the behavior of its members. In addition, elderly people eventually become widow or widower. In addition to high non-monetary costs, widowhood entails economic costs because income and expenditure patterns are altered by changes in the size of the household. Opportunities for economies of scale in joint consumption are lost and resources are no longer shared between household members. ${ }^{1}$ Using a collective household model and data on elderly Swiss households, this paper shows how couples form consumption decisions, provides evidence for substantial economies of scale in consumption, and demonstrates how widowhood affects the standards of living of elderly individuals.

Traditional models of household behavior treat households as single decision makers that maximize household utility subject to some household budget constraint. This simplifies the analysis since standard results of consumer theory can be applied to decisions like the consumption choices of the household. Furthermore, it does not matter who earns which fraction of income. Since only total income is relevant, this approach is referred to as the income pooling hypothesis (Chiappori, 1992). For one-person households, the link of this unitary model to consumer theory is quite natural. Maximizing household utility can be viewed as maximizing the utility function of the consumer subject to her or his budget constraint given by household income that is entirely at the single consumer's disposal. For multi-person households, however, BROwNING and CHIAPPORI (1998) show that the unitary model requires additional strong restrictions, which they reject in the empirical part of their paper. In particular, BROWNING and CHIAPPORI (1998) find evidence against the income pooling hypothesis, meaning that bargaining power matters and income shares have an impact on the composition of goods purchased by the household. Numerous additional articles reject income pooling, examples thereof are SCHULtz (1990), Thomas (1990), Bourguignon et al. (1993), Browning et al. (1994), and Lundberg, Pollak, and Wales (1997).

Increasing criticism of unitary models has led to the development of bargaining models (see, for instance, MANSER and Brown, 1980; McElroy and Horney, 1981) and collective households models initiated by the work of CHIAPPORI (1988)

1 For households of younger couples, the role of children is also important. In a recent paper, Dunbar, Lewbel, and Pendakur (2013) extend collective household models to children. An earlier application of a collective model to children was proposed by BARGAIN and DoNNI (2012)

Swiss Journal of Economics and Statistics, 2017, Vol. 153 (4) 
and Chiappori (1992). Such models account for a possibly unequal distribution of resources among household members, each of whom has their own preferences. Typically, these models only assume that household decisions are Pareto efficient. ${ }^{2}$ More recent collective household models, e.g., Browning, Chiappori, and Lewbel (2013) and Dunbar, Lewbel, and Pendakur (2013), take into account economies of scale in consumption in addition to heterogeneous preferences. Economies of scale arise when goods are jointly consumed by wives and husbands. An example hereof is a couple that travels together by car since gasoline use is only weakly affected by the number of passengers.

This paper addresses the following questions: How are resources allocated to wives and husbands in elderly couples? How large are economies of scale of living together and do they change with retirement? What level of expenditures do widows or widowers need to maintain the same standard of living after the death of the spouse and do actual expenditures correspond to the required level? Answering these questions is important because couples by itself cannot consume. It is individuals who make consumption decisions. The outcome of such decisions therefore should be studied on the level of individuals by exploring how preferences over goods differ between wives and husbands and how they interact to form decisions over the goods purchased by the household. Using a model that addresses individual consumption within couple households further allows us to examine the financial impact of widowhood on the surviving individual. The approach is suitable to study whether the survivors' pension is capable to restore the financial situation of a wife or husband before widowhood and therefore has significant policy implications for the design of pension schemes and supplementary benefits paid to individuals living in poor financial circumstances.

The results indicate that the share of resources allocated to the wife is on average $43.5 \%$ and lies for most couples in the interval between $35 \%$ and $52 \%$. Scale economy estimates show that both spouses save, on average, $27 \%$ or 800 Swiss Francs on monthly expenditures due to jointness of consumption. Resource shares and scale economies are combined to indifference scales that are used to adjust couple households' expenditures to the individual level. Indifference scales are different from traditional equivalence scales as they define how much income an individual living alone would need to attain the same indifference curve over goods that the individual attains as a household member (BROwNING, Chiappori, and Lewbel, 2013). A comparison to actual expenditures of widows and widowers suggests that men suffer a financial loss after losing their

2 There are articles that do not assume Pareto efficient household decisions, see Cherchye, Demuynck, and De Rock (2011) for a recent example. 
wife, while widowed women do not, which is mainly due to the result that more than half of household resources are assigned to husbands. Nevertheless, the estimates indicate that the financial consequences of widowhood are quite small. Inequality measures based on indifference scales show that traditional equivalence scales underestimate inequality among individuals living in couple households by approximately $13 \%$.

The structural model of this paper follows the approach by Lew BeL and PenDAKUR (2008), thus providing the first application of a collective model to elderly Swiss households. Using this class of models, it is therefore the first to study whether the Swiss pension scheme is capable of easing the financial burden of widowhood. Lewbel and Pendakur (2008) provide an empirical application of their model as well, but the group of people they consider is completely different. Their estimates are based on data on singles and couples living in Canada, where all individuals are in the age interval between 25 and 59. The application further differs from the present paper with respect to the number of goods considered. Despite the differences in the setup of the two papers, the results are surprisingly similar. Lewbel and Pendakur (2008) find that $40 \%$ of households' resources are allocated to wives and that cost savings due to economies of scale in consumption are in between $22 \%$ and $30 \%$. This paper is also related to the work by Cherchye, De Rock, and Vermeulen (2012), who apply a different collective household model to data on elderly people in the Netherlands. Their estimates of the female resource shares, however, are substantially larger with an average of $63 \%$. A possible interpretation of this finding is that consumption of Dutch couples is more in line with consumption of wives than it is the case in other countries as Canada or Switzerland. On the other hand, the results could be driven by differences between both models' underlying assumptions required for identification. Finally, the focus on standards of living of elderly people is appealing because of changing economic conditions at the transition from the labor force to retirement and the reduction in the number of individuals in the household due to widowhood.

The structure of the paper is as follows: Section 2 introduces the model in detail and discusses issues of identification. The data used for estimation is described in section 3. Section 4 shows the empirical implementation of the model. The subsequent section 5 presents the main results and provides an analysis of economic well-being and consumption inequality. Section 6 concludes. 


\section{Model}

This paper applies a collective household model, proposed by LEWBEL and PeNDAKUR (2008), to elderly households at the age of transition from the labor force to retirement. The approach allows to estimate how household resources are divided between wives and husbands and to identify the returns to scale from joint consumption. The Lewbel and Pendakur (LP) model is related to the approach by Browning, Chiappori, and Lewbel (2013), which is less restrictive but comes at the cost of requiring data on price variation. ${ }^{3}$ Since data on prices of the goods consumed are not available, this paper sticks to the LP model. ${ }^{4}$

The LP model is a collective household model. Such models do not consider households as a single decision maker. Instead, "the household is characterized as a collection of individuals, each of whom has a well defined objective function, and who interact to generate household level decisions" (LEWBEL and PENDAKUR, 2008, p. 350).

\subsection{Single Households Engel Curves}

Before dealing with the process of intra-household division of resources, consider the consumption decisions of single women and single men. Singles are the only decision maker within their household, therefore their optimal choice of the bundle of goods is the optimal choice of the household. This simplifies the analysis of consumption patterns, since the entire household wealth is at their own disposal and there are no economies of scale in consumption which are potentially arising in multi-person households.

Following the LP model, let $\omega_{j}^{k}\left(\mathbf{p}, x, \mathbf{z}_{j}\right)$ denote the budget share demand function for good $k$ of person $j$ with observable characteristics $\mathbf{z}_{j}$ and $\log$ total expenditures $x$. Person $j$ faces a vector of market prices $p=\left[p^{1}, \ldots, p^{K}\right]^{\prime}$ and decides optimally to spend the fraction $\omega_{j}^{k}\left(\mathrm{p}, x, \mathbf{z}_{j}\right)$ of total expenditures $\left(e^{x}\right)$ on $\operatorname{good} k$, for $k=1, \ldots, K$. Since data on prices are not observed, it is not feasible to exploit any price variation and $\mathrm{p}$ is restricted to a vector of constants. Similar to LP and BüTIKOFER, LEW BEL, and SEITZ (2011), budget shares (Engel curves) are specified as

3 Identification of the Browning, Chiappori, and Lewbel (2013) model does not require assumption 4 that is imposed in section 2.2 .

4 An alternative collective household models that requires data on prices is Cherchye, De Rock, and Vermeulen (2011), whereas the approach by Dunbar, Lewbel, and Pendakur (2013) exploits goods that are assignable. However, the goods that are available for the analysis in this paper are not considered as being assignable. 
a rank three demand system that is quadratic in log total expenditures. BANKs, BLUNDELL, and LEW BEL (1997) show that this specification provides a sufficiently general approximation to Engel curves. Person $j$ is either a woman $(j=f)$ or a man $(j=m)$, which allows budget share demand functions to differ by gender. This distinction seems useful as, for instance, car usage may not be as valuable for women as it is for men and vice versa. The quadratic form for each good $k$ yields a system of $K$ budget-share equations for each type $j$ :

$$
\begin{aligned}
& \omega_{f}^{k}\left(x, \mathbf{z}_{f}\right)=a_{f}^{k 0}+\mathbf{a}_{f}^{k \prime} \mathbf{z}_{f}+\left(x-\mathbf{e}_{f}^{\prime} \mathbf{z}_{f}\right) b_{f}^{k}+\left(x-\mathbf{e}_{f}^{\prime} \mathbf{z}_{f}\right)^{2} c_{f}^{k}+\varepsilon_{f}^{k} \\
& \omega_{m}^{k}\left(x, \mathbf{z}_{m}\right)=a_{m}^{k 0}+\mathbf{a}_{m}^{k \prime} \mathbf{z}_{m}+\left(x-\mathbf{e}_{m}^{\prime} \mathbf{z}_{m}\right) b_{m}^{k}+\left(x-\mathbf{e}_{m}^{\prime} \mathbf{z}_{m}\right)^{2} c_{m}^{k}+\varepsilon_{m}^{k} .
\end{aligned}
$$

Parameters to be estimated are $a_{j}^{k 0}, \mathbf{a}_{j}^{k}, b_{j}^{k}, c_{j}^{k}, \mathbf{e}^{j}$, where letters in bold mark column vectors. The coefficients $b_{j}^{k}$ by itself would only allow for a linear relation between $\log$ expenditures $x$ and budget shares $\omega_{j}^{k}$. The inclusion of $c_{j}^{k}$ captures Engel curvature. Parameter vectors $\mathbf{a}_{j}^{k \prime}$ and $\mathbf{e}_{j}^{\prime}$ permit Engel curves to depend on individual control variables that are denoted by $\mathbf{z}_{f}$ and $\mathbf{z}_{m}$ respectively. The variables $\varepsilon_{j}^{k}$ denote error terms.

\subsection{Resource Shares, Economies of Scale and Indifference Scales}

In the LP model, each household member $j$ determines the demand for consumption goods by maximizing her or his own utility function. Person $j$ 's budget constraint in this maximization problem is given by the share $\eta_{j} \in(0,1)$ of total household expenditures $e^{x}$ that is under control of person $j$, where $\Sigma_{j} \eta_{j}=1$. In logs, personal expenditures of $j$ cannot exceed $\ln \left(\eta_{j} e^{x}\right)=\ln \left(\eta_{j}+x\right)$. The specifications chosen for estimation will allow $\eta_{j}$ to depend on a vector $\mathbf{z}$ including characteristics of the wife $\left(\mathbf{z}_{f}\right)$, of the husband $\left(\mathbf{z}_{m}\right)$ as well as distribution factors $\left(\mathbf{z}_{h}\right)$ that are relevant on the household level. This will formally be indicated by the expression $\eta_{j}(\mathbf{z})$. One can think of $\eta_{j}$ as a measure of bargaining power.

The model includes economies of scale in consumption. That is, some goods consumed by the wife and the husband in a couple household are in total cheaper than the sum of expenditures of two single households who also buy that good. The couple household saves money due to jointness of consumption. In the example of sharing a car, the couple saves money when wife and husband travel together. They nearly need half as much gasoline compared to two singles, each of them traveling in their own car. Of course, car usage does not have to be fully 
public, i.e., members of couple households do not always travel together, sometimes they travel alone.

For goods $k$ that are not purely private, jointness of consumption leads to shadow prices $p_{s}^{k}$ faced by individuals living in couple households that are lower than market prices $p^{k}$, which are relevant for singles. Cost savings for household member $j$ arising from joint consumption are incorporated in the model as illustrated by assumption 1 .

Assumption 1. For $j=f$ and $j=m$, there exists a function $D_{j}\left(\mathbf{z}_{j}\right)$ measuring the cost savings resulting from economies of scale such that it holds for an indirect utility function $V_{j}$

$$
V_{j}\left(\mathbf{p}_{s}, x\right)=V_{j}\left(\mathbf{p}, x-\ln D_{j}\left(\mathbf{z}_{j}\right)\right)
$$

where $\mathrm{p}_{s} \leq \mathbf{p}$.

Assumption 1 states that the utility a person $j$ can achieve when facing shadow prices $\mathbf{p}_{s}$ and total $(\log )$ expenditures $x$ is the same as utility under market prices $\mathrm{p}$ but having expenditures upscaled by some function $D_{j}\left(\mathbf{z}_{j}\right) \in(0,1] . D_{j}\left(\mathbf{z}_{j}\right)$ is an aggregate over goods measure of cost savings that equals 1 when there are no economies of scale, and $D_{j}\left(\mathbf{z}_{j}\right)$ is $<1$ when some goods are shared. Note that assumption 1 restricts $D_{j}\left(\mathbf{z}_{j}\right)$ to be independent of log expenditures $x .^{5}$ As indicated by the dependence on $\mathbf{z}_{j}$, economies of scale are allowed to vary by observable individual characteristics.

To compare singles with wives and husbands living in couple households, not only economies of scale are relevant. Utility comparisons on the individual level need to consider $\eta_{j}\left(\mathbf{z}_{j}\right)$, the sharing rule assigning resources to wives and husbands, and they involve further assumptions. Assumption 2 relates indifference curves of singles to members of couple households.

Assumption 2. For $j=f$ and $j=m$, individual $j$ 's indifference curves over goods remain the same whether living as a member of a couple household or as a single.

Assumption 2 is potentially restrictive, because preferences of wives (husbands) may differ from single women (men), but it is crucial for identification of the LP model. One way to deal with it is to consider only specific types of singles,

5 For a discussion on restrictiveness and testability of the independence assumption, see LEW BEL and Pendakur (2008, p. 353). 
in particular, widows and widowers. This approach is applied for the estimates presented in section 5 and explained in further detail in section 2.4. For the example of car usage, assumption 2 states that the optimal (individual) budget share allocated to cars is the same for women (men) living in couples as it is for women (men) living alone. Two additional assumptions on household behavior are imposed to relate budget share functions of single and couple households:

Assumption 3. Household decision are Pareto efficient.

Assumption 4. Resource shares $\eta_{j}$ are independent of base expenditures $\mathrm{x}$.

Assumption 3 ensures that households do not waste resources. Assumption 4 is essential to derive an expression for budget shares of couple households and implies that resource shares do not affect intertemporal consumption decisions. Assumption 4, however, can be mitigated because the model in principle allows for dependence of resource shares on measures of household wealth other than total expenditures, e.g., household income or education levels. Given these assumptions, LP show that indifference scales allow us to compare the utility of someone living alone to the utility that the same individual would achieve when living in a couple household.

Definition 1. The indifference scale $I_{j}(\mathbf{z})$ puts individual $j$ living alone on the same indifference curve as she or he would attain living in a couple household.

$$
V_{j}\left(\mathrm{p}, x-\ln I_{j}(\mathbf{z})\right)=V_{j}\left(\mathbf{p}_{s}, \ln \eta_{j}(\mathbf{z})+x\right)
$$

The left-hand side of the equation denotes the utility of individual $j$ living alone, the right-hand side describes the utility level achieved by $j$ when living in a couple household. Indifference scales can be used for statements such as: Suppose person $j$ lives in a couple household. If that person was to live alone, for instance, due to widowhood, what fraction of total (couple) household expenditures would be necessary to reach the same indifference curve? The number that answers this question is $\left(1 / I_{j}(\mathbf{z})\right){ }^{6}{ }^{6}$ LP show that the indifference scale is given by the scale economy parameter divided by the measure of resource shares. That is,

$$
I_{j}(\mathbf{z})=\frac{D_{j}\left(\mathbf{z}_{j}\right)}{\eta_{j}(\mathbf{z})} .
$$

6 Non-monetary costs as the emotional impact of losing the spouse are not part of the analysis. 
An appealing property of the LP setup is that indifference scales are invariant to how utility is cardinalized, which is not the case for traditional equivalence scales. ${ }^{7}$

\subsection{Couple Households Engel Curves}

Based on resource shares and indifference scales as defined in section 2.2, LP show that the budget share demand functions of couple households, denoted by $\omega_{h}^{k}(x, \mathbf{z})$, are

$$
\omega_{h}^{k}(x, \mathbf{z})=\sum_{j} \eta_{j}(\mathbf{z})\left[\psi_{j}^{k}\left(\mathbf{z}_{j}\right)+\omega_{j}^{k}\left(x-\ln I_{j}(\mathbf{z}), \mathbf{z}_{j}\right)\right]
$$

for a fixed price regime and some good $k . \psi_{j}^{k}\left(\mathbf{z}_{j}\right)=\left(\partial \ln D_{j}\left(\mathbf{z}_{j}\right) / \partial \ln p_{k}\right)$, the elasticity of $D_{j}\left(\mathbf{z}_{j}\right)$ with respect to the price of good $k$, is constant when prices are invariant. Equation (4) shows that the couple household budget shares are essentially a weighted sum of individual budget shares, adjusted by some constant $\Psi^{k}=\Sigma_{j} \eta_{j}(\mathbf{z}) \psi_{j}^{k}\left(\mathbf{z}_{j}\right)$. The weights are given by the resource shares $\eta_{j}(\mathbf{z})$. Hence, the budget share a couple allocates to cars is more or less a weighted sum of the shares chosen by each household member individually. Household total expenditures $x$ downscaled by the indifference scale $I_{j}(\mathbf{z})$ lead to the expenditure level that is relevant for the choice of (individual) budget shares of household member $j$. It is useful to drop the index $j$ from the resource share parameter. Since only couples of wives and husbands are considered, let $\eta(\mathbf{z})$ denote the resource share of the wife. Consequently, the share of the husband is $(1-\eta(\mathbf{z}))$. Combining equation (4) with equations (1) and (2) yields a system of $K$ equations to be estimated for couple households:

$$
\begin{aligned}
\omega_{b}^{k} & =\eta(\mathbf{z})\left[\begin{array}{l}
a_{f}^{k 0}+\mathbf{a}_{f}^{k \prime} \mathbf{z}_{f}+\left(x-\ln I_{f}(\mathbf{z})-\mathbf{e}_{f}^{\prime} \mathbf{z}_{f}\right) b_{f}^{k} \\
+\left(x-\ln I_{f}(\mathbf{z})-\mathbf{e}_{f}^{\prime} \mathbf{z}_{f}\right)^{2} c_{f}^{k}+\psi_{f}^{k}\left(\mathbf{z}_{f}\right)
\end{array}\right] \\
& +(1-\eta(\mathbf{z}))\left[\begin{array}{l}
a_{m}^{k 0}+\mathbf{a}_{m}^{k \prime} \mathbf{z}_{m}+\left(x-\ln I_{m}(\mathbf{z})-\mathbf{e}_{m}^{\prime} \mathbf{z}_{m}\right) b_{m}^{k} \\
\left.+x-\ln I_{m}(\mathbf{z})-\mathbf{e}_{m}^{\prime} \mathbf{z}_{m}\right)^{2} c_{m}^{k}+\psi_{m}^{k}\left(\mathbf{z}_{m}\right)
\end{array}\right] \\
& +\varepsilon_{b}^{k} .
\end{aligned}
$$

\footnotetext{
7 See Lewbel and Pendakur (2008, p. 352) for the proof.
} 
It remains to parametrize how indifference scales $I_{j}$, resource shares $\eta$, and price elasticities $\psi_{j}^{k}$ are allowed to vary by observable characteristics $z$. This component of the model is clarified in section 4.1.

\subsection{Identification}

The model consisting of equations (1), (2) and (5) is identified given expenditure data for couple households, single women and single men. Assumption 2 allows to express couple budget shares as a function of individual budget shares, as shown in equation (4). When expenditure data for couples and women as well as men living alone are observed, budget shares $\omega_{b}^{k}, \omega_{f}^{k}$ and $\omega_{m}^{k}$ are identified for each $k$. Identification of resource shares $\eta$ and indifference scales $I_{j}$ requires Engel curves that are nonlinear and different across goods as well as across people. Suppose in contrary $\omega_{f}^{k}$ and $\omega_{m}^{k}$ were equivalent, then "weights" of the sum in equation (4) would not matter and $\eta_{j}$ would not be identified. Nonlinearity and variation across goods is required to identify all $b_{j}^{k}$ and $c_{j}^{k}$ parameters and the indifference scales. Linear functions instead would not identify $c_{j}^{k}$. When everything else is known, the constant parameters $\Psi^{k}$, capturing the price elasticity of $D_{j}$, are identified as well. ${ }^{8}$ In principle, the Engel curves need to be different for at least as many goods as there are people in the households to identify the resource shares, the scale economies, and thereby the indifference scales. As the present paper exploits data on five goods and two household members, this means that $\eta_{j}$ and $I_{j}$ are basically overidentified. Nevertheless, the option of using a limited number of goods to conduct specification tests is not considered because the estimates of the scale economies are already rather imprecise when all goods are included. First, this might be a consequence of the relatively low number of singles in the data. Second, the precision could potentially be improved by the inclusion of goods that are assignable, i.e., goods consumed by an individual household member that is known to the researcher. This is, however, not the case for the goods in the available data.

Assumption 2 imposes that the preference structures of individuals need to be independent with respect to their status as a family. However, when comparing data of all singles with members of couple households, this assumption could be violated due to the fact that marriage is not randomly assigned. The results shown in section 5 are estimated using data on couples, widows and widowers

8 For a more detailed and technical proof of identification in the LP model, see LEwBeL and Pendakur (2008, p. 353). 
only. Widows and widowers are singles that once decided to get married. Therefore, they are not likely to be systematically different from people living in couple households.

\section{Data}

The model introduced in section 2 is estimated using data from the Swiss Household Budget Survey (HBS), conducted by the Swiss Federal Statistical Office. Besides key individual attributes, this dataset provides comprehensive monthly expenditure data at the household level for various goods and services. This study explores pooled cross-section data of the years 2000 to 2005, adjusted for inflation, for one- and two-person households where the sample is restricted to households consisting of members that are between 50 and 80 years old. Individuals in this age bracket are of economic interest since they pass the transition from the labor force to retirement. The sample consists of 3459 married couples, 1034 single women and 316 single men. All singles live in one-person households and 823 of them are widowed (669 widows and 154 widowers). ${ }^{10}$

Individual control variables used for the estimation of the Engel curves are retirement status, education and age of each household member. The retirement and education variables are dummies. The former is 1 for those that are retired ( 0 otherwise) and the latter equals 1 for individuals with tertiary education ( 0 for lower education levels). Controlling for the age of each individual is important because expenditures on some goods decline when people get older. For couple households, an additional binary variable indicating whether the wife or the husband earns more is included. ${ }^{11}$ If the wife provides the larger fraction of household income, this binary indicator equals 1 , otherwise 0 .

Summary statistics of the demographic characteristics are shown in Table 1. On average, widows and widowers are older and more often retired than singles and married couples. Single women tend to have relatively high levels of education, while educational achievements of widows are lower and similar to wives in

9 This is a common strategy in the literature on collective household models. See, for instance, Cherchye, De Rock, and Vermeulen (2012) or Michaud and Vermeulen (2011). A general discussion is provided by CHerchye et al. (2015).

10 Individuals living in elderly homes and individuals living with other family members are excluded as they do not necessarily make their own consumption decisions.

11 It would be preferable to have a more comprehensive measure of individual contributions to household income. This information, however, is not available in the HBS data. 
couple households. This comparison indicates that widows are similar in terms of eduction to women living in couples. Nevertheless, the averages could still be affected by differences in the age compositions. For men, education levels are the highest for married husbands. For $7 \%$ of couple households, the wife earns more than her husband. ${ }^{12}$

Table 1: Mean Characteristics (z Vectors)

\begin{tabular}{lcccccc}
\hline & $\begin{array}{c}\text { Widowed } \\
\text { women }\end{array}$ & $\begin{array}{c}\text { Widowed } \\
\text { men }\end{array}$ & $\begin{array}{c}\text { Single } \\
\text { women }\end{array}$ & $\begin{array}{c}\text { Single } \\
\text { men }\end{array}$ & $\begin{array}{c}\text { Married } \\
\text { women }\end{array}$ & $\begin{array}{c}\text { Married } \\
\text { men }\end{array}$ \\
\hline Retired & 0.86 & 0.82 & 0.78 & 0.61 & 0.47 & 0.58 \\
Education & 0.07 & 0.25 & 0.10 & 0.27 & 0.07 & 0.31 \\
Age & 71.09 & 70.82 & 69.31 & 65.76 & 63.09 & 65.51 \\
Wife earns more & & & & & \multicolumn{2}{c}{0.07} \\
\hline Observations & 669 & 154 & 1034 & 316 & 3459 & 3459 \\
\hline
\end{tabular}

Note: Singles include widows and widowers. Data source: Household Budget Survey (HBS).

Six expenditure categories are considered: food products and nonalcoholic beverages, housing, housekeeping, transportation, entertainment and recreation and culture, and telecommunication. ${ }^{13}$ These expenditures have been chosen because they include goods and services on which households can freely choose how much to spend. This would, for instance, not be the case for health insurance premiums. ${ }^{14}$ Note that food and non-alcoholic beverages denote products consumed at home. Housing contains the rent or mortgage interest payment and energy cost of the principal residence. Housekeeping includes ordinary household

12 The share is $12 \%$ for couples where the husband is retired but the wife is still working. Complementary data of the years 2000 to 2005 on elderly couples (aged 50 to 80) from the Swiss Household Panel corroborates the finding that husbands typically provide the larger fraction of household income (http://www.swisspanel.ch, accessed July 2016). In this data, however, the average individual age is 3 years lower and the wife earns more for roughly $20 \%$ of the couple households.

13 This is similar to most of the literature. See, e.g., Browning, Chiappori, and Lew bel (2013), Cherchye, De Rock, and Vermeulen (2012), or Lew bel and Pendakur (2008). Expenditures on alcohol and tobacco are excluded because they are small and many households report zero expenditures. Similarly, a substantial fraction of all observations reported zero expenditures for clothing which makes the estimation of the Engel curves difficult.

14 Health insurance is compulsory for the entire population in Switzerland and independent of employment. It is offered by private insurance companies that are subject to strong regulations. 
expenditures such as home textiles, home appliances, tools, furniture, or decoration but excludes comestible goods. Transportation excludes car purchases because these are exceptionally large and infrequent expenditures that distort ordinary monthly expenditures. Expenditures on furniture, which could also be considered as durables, are not excluded because they are more frequent than car purchases and their impact on total expenditures is considerably smaller. ${ }^{15}$

The distribution of expenditures across household types is shown in Table 2. Single women assign two percentage points more of their expenditures to food products and nonalcoholic beverages as well as to housing than single men. Single men, on the other hand, spend five percentage points more on transportation than single women. These differences are significant on the 5\% level and they are of the same magnitude when widows are compared to widowers. Even though the differences are small for budget shares of other goods, the descriptive statistics reveal the importance of models allowing for unequal preferences among members of multi-person households. Moreover, the gender differences in the budget shares allocated to housing have implications on couple household behavior as housing constitutes a stereotype example of a shared good. Individuals' preferences over goods stay the same whether they are living alone or as a member of a couple household by assumption 2. For couples, the shared good housing therefore comprises a higher fraction of the wives' consumption as it is the case for husbands. In other words, this finding indicates that women are willing to allocate more resources than men to goods that generate utility to all household members. Nevertheless, couples' budget shares related to housing are considerably lower than corresponding shares of one-person households, the differences are in between seven and ten percentage points and they are significant on the $1 \%$ level. This sharp difference between couples and individuals living alone indicates that couples save on housing expenditures by living together, which can be seen as joint consumption. In contrast, couples spend a significantly higher share on food products and nonalcoholic beverages. These goods can be considered as private and are typically not consumed jointly. For other goods, the differences are small.

Table 3 summarizes budget shares for married couples differentiated by retirement status. Expenditures related to home production as food products and nonalcoholic beverages tend to receive slightly higher budget shares in households where at least one member is retired. This finding supports the hypothesis that retirees are likely to use their additional free time for home production of food

15 When only non-zero expenditures are considered, the averages are 193 Swiss Francs for furniture and 4247 Swiss Francs for car purchases. 
Table 2: Mean Budget Shares by Household Type

\begin{tabular}{lccccc}
\hline & $\begin{array}{c}\text { Widowed } \\
\text { women }\end{array}$ & $\begin{array}{c}\text { Widowed } \\
\text { men }\end{array}$ & $\begin{array}{c}\text { Single } \\
\text { women }\end{array}$ & $\begin{array}{c}\text { Single } \\
\text { men }\end{array}$ & $\begin{array}{c}\text { Married } \\
\text { couples }\end{array}$ \\
\hline $\begin{array}{l}\text { Food Products and } \\
\text { Nonalcoholic Beverages }\end{array}$ & 0.22 & 0.20 & 0.21 & 0.19 & 0.26 \\
Housing & 0.47 & 0.44 & 0.47 & 0.45 & 0.37 \\
Housekeeping & 0.06 & 0.06 & 0.06 & 0.06 & 0.07 \\
Transportation & 0.08 & 0.13 & 0.08 & 0.13 & 0.12 \\
$\begin{array}{l}\text { Entertainment, Recreation, } \\
\text { Culture }\end{array}$ & 0.13 & 0.13 & 0.14 & 0.14 & 0.14 \\
Telecommunication & 0.04 & 0.04 & 0.04 & 0.04 & 0.04 \\
\hline Observations & 669 & 154 & 1034 & 316 & 3459 \\
\hline
\end{tabular}

Notes: Singles include widows and widowers. Transportation excludes car purchases. Data source: Household Budget Survey (HBS).

Table 3: Mean Budget Shares for Couples by Retirement Status

\begin{tabular}{lcccc}
\hline & $\begin{array}{c}\text { Both } \\
\text { Working }\end{array}$ & $\begin{array}{c}\text { Wife } \\
\text { Retired }\end{array}$ & $\begin{array}{c}\text { Husband } \\
\text { Retired }\end{array}$ & $\begin{array}{c}\text { Both } \\
\text { Retired }\end{array}$ \\
\hline Food Products and Nonalcoholic Beverages & 0.24 & 0.26 & 0.26 & 0.28 \\
Housing & 0.39 & 0.38 & 0.36 & 0.35 \\
Housekeeping & 0.07 & 0.07 & 0.07 & 0.07 \\
Transportation & 0.13 & 0.11 & 0.12 & 0.12 \\
Entertainment, Recreation, Culture & 0.14 & 0.15 & 0.15 & 0.14 \\
Telecommunication & 0.04 & 0.04 & 0.04 & 0.04 \\
\hline Observations & 1283 & 247 & 634 & 1295 \\
\hline
\end{tabular}

Notes: Singles include widows and widowers. Transportation excludes car purchases. Data source: Household Budget Survey (HBS). 
and related products. Budget shares allocated to housing are lower for retirees. Other goods show little variation by retirement status.

\section{Empirical Implementation}

\subsection{Parametrization}

Parametric forms chosen for this paper follow, with an exception concerning the price elasticities of $D_{j}\left(\mathbf{z}_{j}\right)$, the specifications proposed by LEWBEL and PENDAKUR (2008). That is, the resource share of the wife $\eta(\mathbf{z})$, and consequently $(1-\eta(\mathrm{z}))$ for the husband, is parametrized to be linear in individual and household characteristics.

$$
\eta(\mathbf{z})=\mathbf{r}^{\prime} \mathbf{z}=r_{0}+\mathbf{r}_{b}^{\prime} \mathbf{z}_{b}+\mathbf{r}_{f}^{\prime} \mathbf{z}_{f}+\mathbf{r}_{m}^{\prime} \mathbf{z}_{m}
$$

The cost savings functions $D_{j}\left(\mathbf{z}_{j}\right)$, resulting from economies of scale when living with others, are specified to be log-linear in individual characteristics. Moreover, they are parametrized to be gender specific because the budget shares are different for wives and husbands.

$$
\begin{aligned}
& \ln D_{f}\left(\mathbf{z}_{f}\right)=d_{0 f}+\mathbf{d}_{f}^{\prime} \mathbf{z}_{f} \\
& \ln D_{m}\left(\mathbf{z}_{m}\right)=d_{0 m}+\mathbf{d}_{m}^{\prime} \mathbf{z}_{m}
\end{aligned}
$$

Equation (3) shows that log indifference scales can be expressed as the difference of log cost savings and log resource shares. With the parametrizations of equations (6), (7) and (8), this yields parametric expressions for log indifference scales.

$$
\begin{aligned}
\ln I_{f}(\mathbf{z}) & =\ln D_{f}\left(\mathbf{z}_{f}\right)-\ln \eta(\mathbf{z}) \\
& =d_{0 f}+\mathbf{d}_{f}^{\prime} \mathbf{z}_{f}-\ln \left(r_{0}+\mathbf{r}_{b}^{\prime} \mathbf{z}_{b}+\mathbf{r}_{f}^{\prime} \mathbf{z}_{f}+\mathbf{r}_{m}^{\prime} \mathbf{z}_{m}\right) \\
\ln I_{m}(\mathbf{z})= & \ln D_{m}\left(\mathbf{z}_{m}\right)-\ln (1-\eta(\mathbf{z})) \\
= & d_{0 m}+\mathbf{d}_{m}^{\prime} \mathbf{z}_{m}-\ln \left(1-\left(r_{0}+\mathbf{r}_{b}^{\prime} \mathbf{z}_{h}+\mathbf{r}_{f}^{\prime} \mathbf{z}_{f}+\mathbf{r}_{m}^{\prime} \mathbf{z}_{m}\right)\right)
\end{aligned}
$$

It remains to parametrize the elasticities of $D_{j}\left(\mathbf{z}_{j}\right)$ with respect to prices of goods $k$, denoted by $\psi_{j}^{k}\left(\mathbf{z}_{j}\right)$. In general, these parameters can be different for wives and husbands $(j=f, m)$ and depend on individual characteristics $\mathbf{z}_{j}$. In the HBS data, 
however, there is limited variation to identify these parameters. The specification of this paper allows these coefficients to differ by gender $j$, but not to depend on further covariates.

$$
\begin{aligned}
& \psi_{f}^{k}\left(\mathbf{z}_{f}\right)=\delta_{f}^{k} \\
& \psi_{m}^{k}\left(\mathbf{z}_{m}\right)=\delta_{m}^{k}
\end{aligned}
$$

The structure imposed by equations (11) and (12) is not considered to be particularly restrictive. An alternative approach, followed by BütiKOfER, Lew BEL, and Seitz (2011), would be to omit $\psi_{j}^{k}\left(\mathbf{z}_{j}\right)$. Results for this specification, which reduces the number of estimands, are reported in the appendix (section B2).

\subsection{Estimation}

The vectors of individual control variables, $\mathbf{z}_{f}$ and $\mathbf{z}_{m}$, include retirement status, education and age. Included in $\mathbf{z}_{b}$ as a distribution factor is the binary variable indicating who is the main contributor to household income. Engel curves are estimated for all goods except telecommunication because budget shares sum to 1. In summary, this model for 3 types of households and five different goods leads to a system of $3 \times 5$ equations that are jointly estimated by nonlinear seemingly unrelated regression. Similar to Lewbel and Pendakur (2008), precision of the estimates is examined using asymptotic standard errors (calculated by Gauss-Newton regression). Joint estimation of a total of 92 parameters is inevitable since the model contains parameter restrictions over budget share equations of different goods as well as over household types. 


\section{Results}

This section presents the main results for the resource share and economy of scale parameters, provides an analysis of the economic well-being among widows and widowers, and shows how sharing of resources within households affects inequality among individuals.

\subsection{Resource Shares and Scale Economies}

The coefficients and corresponding standard errors for the resource share and economy of scale parameters are reported in Table 4. The estimates of all Engel curve parameters are in the appendix (Table 8). The model is estimated using normalized covariates such that a vector of zeros corresponds to an individual that is not retired, has no tertiary education and is 60 years old. For couples, the additional normalization that the husband is the main contributor to household income is imposed. This normalization allows for a meaningful interpretation of the intercepts as estimates for a well defined reference group.

For couples where the husband earns more than his wife, where both spouses are still in the labor force, have no tertiary education and are 60 years old, the wife is estimated to receive the fraction $\eta=0.462$ with a standard error (SE) of 0.056 , which is $46.2 \%$ of household resources. The point estimate indicates that slightly less than half of household resources are allocated to the wife. Note, however, that equal shares of $50 \%$ are inside the $95 \%$ confidence interval. When the wife earns more, her share is estimated to significantly increase by 2 percentage points, indicating that additional income increases her bargaining power. The share of resources allocated to the wife is estimated to be lower for older couples. Increasing the age of both spouses by 5 years significantly reduces the fraction assigned to the wife by 3.7 percentage points (SE: 1.3 percentage points). A possible interpretation for this finding is that women lose bargaining power when they get older. On the other hand, it might as well be the case that couples of older generations allocate less resources to wives. It is, however, not possible to disentangle these effects as each household is only observed once. Panel data would be required to assess whether the share of the wife declines over time or if it is generally lower for older age groups. Nevertheless, the model allows us to study the effect of age differences on the sharing rule. Increasing only the age of the husband by 5 years decreases the share of the wife by 3.0 percentage points (SE: 1.0 percentage points), showing that the overall age effect is largely driven by the effect for men. Education and retirement status have small and insignificant effects on how resources are divided within couples. Note that the education 
level of wives and husbands is highly correlated within households. For $73 \%$ of all couples in the data, the binary education variable is the same for both spouses.

Table 4: Sharing Rule and Scale Economy Parameter Estimates

\begin{tabular}{lccc}
\hline & $\begin{array}{c}\text { Sharing rule } \\
\eta(\mathbf{z})\end{array}$ & $\begin{array}{c}\text { Wife scale economy } \\
\ln D_{f}\left(\mathbf{z}_{f}\right)\end{array}$ & $\begin{array}{c}\text { Husband scale economy } \\
\ln D_{m}\left(\mathbf{z}_{m}\right)\end{array}$ \\
& Estimate & Estimate & Estimate \\
Intercept & $0.462^{* * *}$ & -0.214 & -0.217 \\
& $(0.056)$ & $(0.135)$ & $(0.172)$ \\
Wife earns more & $0.020^{*}$ & & \\
& $(0.011)$ & & \\
Wife retired & -0.009 & -0.139 & -0.060 \\
& $(0.010)$ & $(0.092)$ & $(0.109)$ \\
Husband retired & 0.016 & & 0.100 \\
& $(0.014)$ & -0.013 & $(0.076)$ \\
Education wife & 0.009 & $(0.113)$ & \\
Education husband & $(0.013)$ & & $-0.023^{* *}$ \\
& 0.009 & & $(0.009)$ \\
\hline Age wife & $(0.010)$ & $-0.012^{*}$ & \\
& -0.001 & & \\
Age husband & $(0.001)$ & & \\
& $-0.006^{* * *}$ & & \\
\hline
\end{tabular}

Notes: Number of observations: 4282. Number of parameters in the model: 92. Significance levels: ${ }^{*} 10 \%,{ }^{* *} 5 \%,{ }^{* * *} 1 \%$. Standard error in parentheses.

Figure 1 shows the histogram of estimated female resource shares $\eta(\mathbf{z})$ for all couples in the sample. These shares have an average of $43.5 \%$ and a median of $43.9 \%$. For $90 \%$ of all couples, resource shares of wives are estimated to lie in the interval between $35 \%$ and $52 \%$, indicating that the bargaining process is beneficial for husbands. ${ }^{16}$ The estimates are comparable to the results of Lewbel and Pendakur (2008) who find shares between $36 \%$ and $46 \%$. Specifically for elderly households, diverging results are reported in the literature. BüTIKOFER, Lew bel, and Seitz (2011), using data from the United States, find that approximately $33 \%$ are allocated to the wife. For a different model, Cherchye, De Rock, and Vermeulen (2012) estimate shares in the order of $63 \%$.

16 All female resource shares are predicted to lie in the interval between $31 \%$ and $55 \%$. 
Figure 1: Histogram of Estimated Female Resource Shares $\eta(\mathrm{z})$

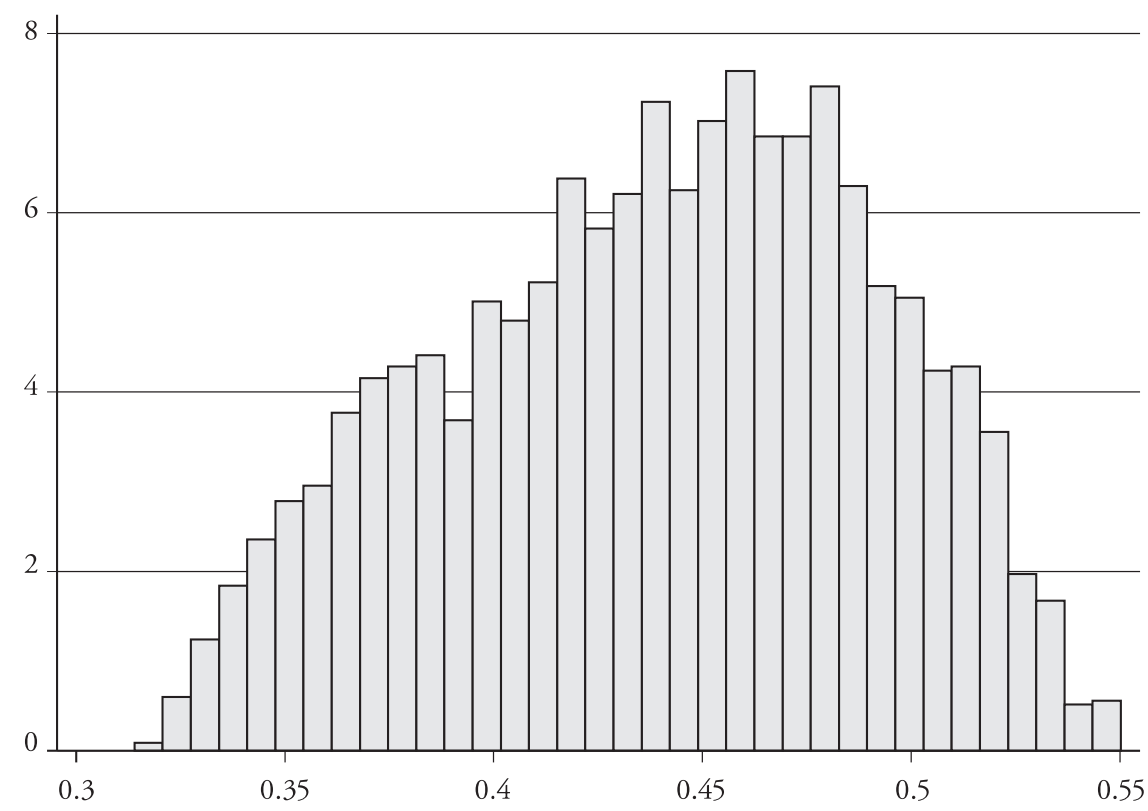

Table 4 also shows that economies of scale arising from joint consumption reduce the expenditures necessary to reach some level of utility. When the covariates are normalized to a vector of zeros, wives living in couple households are estimated to face the fraction $D_{f}=\exp (-.214)=80.7 \%$ of the cost that arise for widows who face market prices. Husbands are estimated to face $80.5 \%$ of the cost. Note, however, that these intercept parameters are not precisely estimated with standard errors of 0.135 and 0.172 respectively. ${ }^{17}$ The cost savings of wives and husbands significantly increase when they get older. Retirement tends to augment scale economies as well. This is plausible because former workers are likely to spend considerably more time at home when they retire. A wife who is 65 years old and retired is estimated to face $66.2 \%$ of the cost of a widow. ${ }^{18}$ The estimate for a husband who is 65 and retired is $67.6 \%$. Higher education does not have

17 The parameters of the sharing rule are more precisely estimated than those constituting the scale economies. This pattern also occurs in alternative specifications and is similar to the standard errors reported in the application of Lewbel and Pendakur (2008).

18 The calculation of $D_{f}$ for illustration: $0.662=\exp (-.214-.139-5 \times .012)$. 
an impact on the economies of scale of wives, but is found to have a negative impact for husbands. To some extent, this finding indicates that well educated men tend to purchase less goods than can jointly be consumed. When integrated over the covariate distribution, the average estimates are $73.5 \%$ for $D_{f}$ and $72.0 \%$ for $D_{m}$, meaning that wives (husbands) save $26.5 \%$ (28\%) on expenditures due to economies of scale in consumption.

The results for resource shares and economies of scale allow us to construct estimates of indifference scales. For the reference group (couples where both spouses are 60 years old, not retired, do not have higher education and where the husband is the main contributor to household income), the point estimates of the indifference scales are $I_{f}=1.746$ and $I_{m}=1.497$ with standard errors of 0.162 for $I_{f}$ and 0.184 for $I_{m}$. These results indicate that wives need $57.3 \%(=1 / 1.746)$ of total couple households resources to maintain the same standard of living when becoming a widow. The estimate, however, increases to $65.6 \%$ when both spouses are 65 years old and retired, mainly because of larger returns to scale in consumption after retirement. Husbands in the reference group are estimated to need $66.8 \%(=1 / 1.497)$.

\subsection{Economic Well-Being among Widows and Widowers}

Based on the parameter estimates in section 5.1, indifference scales can be constructed for each person in the sample. These scales depend on individual as well as household characteristics and allow to compare utility levels of members of couple households to individuals living alone, in this case to widows and widowers. This comparison helps to investigate the economic (monetary) consequences of widowhood. Non-monetary costs of losing the spouse are not part of the analysis. The sample median inverse indifference scale for wives in couple households $\left(1 / I_{f}\right)$ is $59.0 \%$ of household resources, the median for husbands is $79.9 \% .^{19}$ Female indifference scales are distributed in a small interval, whereas male indifference scales have a larger variance due to the less precise estimates of $D_{m}$ compared to $D_{f}$ Note that for one-person households, e.g., widows and widowers, the indifference scale is $100 \%$ by construction. Table 5 shows the mean and three quartiles of the expenditure distribution for widows, widowers and couple households (not adjusted by any scale). Only expenditures on goods and services used for estimation of the model are included in the numbers shown in

19 The median of female resource shares $(\eta)$ is $43.9 \%$. The medians of the cost savings functions are 0.733 for $D_{f}$ and 0.700 for $D_{m}$. 
the table. ${ }^{20}$ Table 6 compares these quantities to the corresponding means and quantiles of couple households, adjusted by an equivalence scale as well as indifference scales. The equivalence scale is the scale proposed by the Organisation for Economic Co-operation and Development (OECD) that divides household level variables by 1.5 . The downscaling is the same for husbands and wives and thereby imposes the assumption of equal intra-household division of resources.

The summary statistics of Table 5 show that widowers are often in a better financial situation than widows and are therefore able to spend more on consumption. Their mean and median expenditures are larger by roughly 300 Swiss Francs per month compared to widows. Higher expenditures are affordable for widowers because their salary or pension tends to be larger. To some extent, higher pensions paid to men can be explained by the structure of the Swiss pension system, which is classified in three complementary institutions called pillars. Besides the compulsory social insurance for the entire country (first pillar) and mandatory occupational pensions (second pillar), individuals can voluntarily save for retirement by contributing to a private pension plan (third pillar). While the first pillar consists of a pay-as-you-go system that caps benefits at a relatively low level, the second pillar as well as the third pillar are fully-funded pension systems. The second- and third-pillar benefits are therefore determined by the amount of individual contributions which are often higher for men because of larger salaries and more years of employment. Moreover, survivors' pensions paid to widows (and widowers) by the compulsory social insurance are relatively low with rates between 940 and 1880 Swiss Francs per month. Similarly, the additional second pillar transfer to a widow (or widower) is lower than the old age pension paid to the spouse before death. ${ }^{21}$ The low quantiles of the expenditure distribution of widowers are close to the ones of widows. This finding can be explained by supplementary benefits paid to individuals or couples living in poor financial circumstances to cover basic expenditures.

Couple households expenditures adjusted by the OECD equivalence scale are in the range of expenditure levels of widowers and widows (Table 6). In particular, mean expenditures indicate that individuals in couples are slightly better off than widows but worse off than widowers. While average monthly expenditures of widows are $3.1 \%$ lower, those of widowers are $12.8 \%$ higher.

20 This is because the indifference scales are estimated based on these goods and services.

21 See, e.g., https://www.ahv-iv.ch/p/3.03.e (accessed July 2016) for information on first-pillar benefits and http://www.bsv.admin.ch/themen/vorsorge/00039/00335/index.html?lang=en (accessed July 2016) for the second pillar. 
Table 5: Expenditures by Household Type

\begin{tabular}{ll|ccc}
\hline & Mean & \multicolumn{3}{|c}{ Percentiles } \\
& & $25 \%$ & $50 \%$ & $75 \%$ \\
\hline Widows & 2000.5 & 1459.2 & 1815.4 & 2285.2 \\
Widowers & 2328.7 & 1414.1 & 2097.8 & 2816.6 \\
Couples & 3095.7 & 2141.7 & 2828.4 & 3727.8 \\
\hline
\end{tabular}

Note: Measured in Swiss Francs per month, adjusted to the price level of the year 2000.

Indifference scales show that economies of scale in consumption and the intrahousehold bargaining process are particularly beneficial for husbands. Therefore a husband needs high expenditures to maintain the same standard of living when his wife dies. Compared to the means of actual expenditures reported by widows and widowers, only men suffer a financial loss when becoming widower. While women are estimated to need 1842 Francs per month to maintain the same standard of living, mean expenditures of widows are roughly 160 Francs higher. Men are estimated to need 2466 Francs. Actual expenditures of widowers are, however, 137 Francs lower. That is, widowers are estimated to lose $5.6 \%$, while widows in fact have $8.6 \%$ higher expenditures at their disposal. Therefore, to avoid a loss in the standard of living, widowers would require additional survivor' pensions or supplementary benefits. Nevertheless, these numbers also indicate that the financial consequences of losing the spouse are relatively small and that the Swiss pension scheme is capable of easing the financial burden of widowhood.

Table 6: Expenditures Assigned to Individuals in Couple Households

\begin{tabular}{lc|ccc}
\hline & Mean & \multicolumn{3}{|c}{ Percentiles } \\
& & $25 \%$ & $50 \%$ & $75 \%$ \\
\hline $\begin{array}{l}\text { OECD equivalence scale } \\
\text { Individuals in couples }\end{array}$ & 2063.8 & 1427.8 & 1885.6 & 2485.2 \\
\hline $\begin{array}{l}\text { Indifference scales } \\
\text { Women in couples }\end{array}$ & 1842.1 & 1265.0 & 1675.0 & 2231.9 \\
$\quad$ Men in couples & 2465.7 & 1696.7 & 2253.1 & 2946.2 \\
\hline
\end{tabular}

Notes: Measured in Swiss Francs per month, adjusted to the price level of the year 2000. The (modified) OECD equivalence scale divides expenditures of couple households by 1.5 . 
In summary, while widowers are often financially better off than widows, their loss compared to the situation living in couple households is larger. First, this is because more than half of household resources are allocated to husbands. Second, their returns to scale in consumption seem, although not very precisely estimated, to be quite large.

\subsection{Consumption Inequality}

As shown by Lise and SeITZ (2011), inequality is likely to be underestimated when ignoring within-household inequality. In this section, inequality measures are computed for couple households, widows and widowers. The first three rows of Table 7 show the commonly used Theil and Gini indices for these types of households. The numbers indicate that consumption inequality among widows is similar to inequality among couples. Inequality among widowers is slightly higher. The indices for couple households are based on total household expenditures. Using total household expenditures entails the assumption of no withinhousehold inequality, which is implicitly done by equivalence scales. Therefore, couples' expenditures adjusted to the individual level by any equivalence scale does not change the inequality measures (row four of Table 7).

Table 7: Consumption Inequality

\begin{tabular}{lcc}
\hline & Theil index & Gini index \\
\hline Widows & 0.090 & 0.229 \\
Widowers & 0.119 & 0.268 \\
Couples & 0.092 & 0.238 \\
\hline $\begin{array}{l}\text { Equivalence scale } \\
\text { Individuals in couples }\end{array}$ & 0.092 & 0.238 \\
\hline $\begin{array}{l}\text { Indifference scales } \\
\text { Individuals in couples }\end{array}$ & 0.104 & 0.251 \\
\hline
\end{tabular}

In contrast, indifference scales consider inequality among couple households taking into account the unequal distribution of resources between wives and husbands. The bottom row of Table 7 shows that both indices increase when couples expenditures are transformed by individual-specific indifference scales. This indicates that traditional equivalence scales tend to underestimate individuallevel inequality because they disregard this potential second factor arising from 
within-household inequality. Based on indifference scales, the additively decomposable Theil index is 0.104 , while it is 0.092 when differences between wives and husbands are ignored. These numbers indicate that $11.5 \%$ of total inequality among women and men living in couple households arises from within household inequality. Other authors report even higher proportions, e.g., BüTIKOFER and Gerfin (2017) find $16 \%$ and Lise and Seitz (2011) estimate that $25 \%$ is due to within household inequality.

\section{Conclusion}

This paper provides an analysis of the standards of living of elderly Swiss households using a model that takes changes in consumption expenditures related to retirement and widowhood into account. While retirement essentially impacts income and expenditure patterns, widowhood alters the composition of a household. As the number of household members declines from two to one, economies of scale arising from joint consumption in couple households disappear. Moreover, resources are no longer shared. Identification and estimation of the LP model applied in this paper is based on household-level expenditure data for couples, widows and widowers. The latter are used to identify preferences of individuals living in couples.

The main findings can be summarized as follows: wives control, on average, $44 \%$ of household resources and both partners save $27 \%$ or 800 Swiss Francs per month on expenditures due to joint consumption of some goods. Retirement is estimated to increase these returns to scale. Resource shares and scale economies are combined to indifference scales that are used to adjust couple households' expenditures to the individual level. A comparison to actual expenditures of widows and widowers suggests that there is a financial loss due to the death of the spouse for men but not for women. Widowers would therefore require additional survivor' pensions to maintain their standard of living. However, as widowers' expenditure levels are mostly above those of widows, this is not likely to be a policy to consider for implementation. Moreover, the estimates indicate that the financial consequences of widowhood are quite small, which is the most important result from a policy perspective. Indifference scales are further useful to examine inequality among individuals. The estimates indicate that $11.5 \%$ of total inequality among women and men living in couple households arises from within-household inequality.

There are limitations that cannot be addressed with the model and available data. First, the results are based on a static model. Any dynamic aspects, as for 
instance the transition process to retirement, cannot be captured. An important extension for future research would therefore be to extend the model to capture dynamics in consumption expenditures but also in retirement decisions. The LP model implicitly assumes that retirement is exogenous. Although most individuals retire during the period of one or two years around the ordinary retirement age, there is still some leeway in decision-making that is not captured by the model and the estimated positive effect of retirement on the returns to scale might therefore be confounded by third factors. Moreover, it is likely to be the case that individuals in poor health are forced to retire earlier. In consequence to the indirect health effect, the reported impact of retirement might not only cover its causal effect. In fact, Bütikofer, Lew bel, and Seitz (2011) find evidence for higher scale economies for individuals in poor health. Neglecting these factors does not distort the size of the estimated resource shares and scale economies per se, but potentially leads to wrong conclusions about the causal impact of individual characteristics. Second, the HBS data does not include time-use data on home production, e.g., cooking. As emphasized by Apps and ReEs (1997), these activities considerably contribute to overall consumption. Aside from these limitations, the present paper provides a suitable first step for the analysis of the financial consequences of widowhood for elderly Swiss households. 


\section{A. Additional Tables}

Table 8: Estimates of the 92 Parameters of the Main Model

\begin{tabular}{|c|c|c|c|c|c|c|c|c|}
\hline & Est & Std Err & & Est & Std Err & & Est & Std Err \\
\hline $\operatorname{am} 10$ & -0.106 & 0.645 & af10 & 5.276 & 0.422 & $\mathrm{r} 0$ & 0.462 & 0.056 \\
\hline $\operatorname{am} 20$ & 0.067 & 0.021 & af 20 & -0.006 & 0.012 & rh 1 & 0.020 & 0.011 \\
\hline $\operatorname{am} 30$ & -0.009 & 0.016 & af30 & -0.068 & 0.013 & $\mathrm{rm} 1$ & 0.016 & 0.014 \\
\hline $\operatorname{am} 40$ & -0.011 & 0.001 & af40 & -0.002 & 0.001 & $\mathrm{rm} 2$ & 0.009 & 0.010 \\
\hline $\operatorname{am} 50$ & -7.889 & 1.128 & af50 & -13.402 & 0.860 & $\mathrm{rm} 3$ & -0.006 & 0.002 \\
\hline $\operatorname{am} 11$ & -0.062 & 0.020 & af1 1 & 0.002 & 0.015 & rf1 & -0.009 & 0.010 \\
\hline $\operatorname{am} 21$ & -0.052 & 0.015 & af 21 & 0.032 & 0.019 & $\mathrm{rf} 2$ & 0.009 & 0.013 \\
\hline $\operatorname{am} 31$ & 0.008 & 0.002 & af31 & 0.004 & 0.001 & rf3 & -0.001 & 0.001 \\
\hline am41 & 0.634 & 0.584 & af41 & 3.367 & 0.412 & $\mathrm{dm} 0$ & -0.217 & 0.172 \\
\hline am51 & -0.020 & 0.011 & af51 & 0.001 & 0.007 & $\mathrm{dm} 1$ & -0.060 & 0.109 \\
\hline $\operatorname{am} 12$ & -0.007 & 0.008 & af 12 & -0.003 & 0.008 & $\mathrm{dm} 2$ & 0.100 & 0.076 \\
\hline $\operatorname{am} 22$ & 0.005 & 0.001 & af 22 & 0.001 & 0.000 & $\mathrm{dm} 3$ & -0.023 & 0.009 \\
\hline $\operatorname{am} 32$ & 0.819 & 0.597 & af32 & 2.410 & 0.413 & dfo & -0.214 & 0.135 \\
\hline am42 & 0.006 & 0.009 & af42 & 0.002 & 0.007 & df1 & -0.139 & 0.092 \\
\hline $\operatorname{am} 52$ & 0.022 & 0.007 & af52 & 0.013 & 0.008 & df 2 & -0.013 & 0.113 \\
\hline $\operatorname{am} 13$ & -0.001 & 0.001 & af13 & 0.000 & 0.000 & df3 & -0.012 & 0.007 \\
\hline $\operatorname{am} 23$ & 6.936 & 0.774 & af 23 & 2.866 & 0.468 & $\delta \mathrm{m} 1$ & 0.426 & 0.161 \\
\hline $\operatorname{am} 33$ & 0.006 & 0.011 & af33 & 0.001 & 0.008 & $\delta \mathrm{m} 2$ & -0.327 & 0.136 \\
\hline $\operatorname{am} 43$ & 0.037 & 0.009 & af43 & 0.035 & 0.009 & $\delta \mathrm{m} 3$ & -0.122 & 0.061 \\
\hline $\operatorname{am} 53$ & -0.001 & 0.001 & af53 & -0.002 & 0.000 & $\delta \mathrm{m} 4$ & -0.036 & 0.032 \\
\hline bm 1 & 0.245 & 0.171 & bf1 & -1.222 & 0.114 & $\delta \mathrm{m} 5$ & 0.070 & 0.046 \\
\hline $\mathrm{bm} 2$ & 2.195 & 0.295 & bf 2 & 3.632 & 0.226 & $\delta \mathrm{f} 1$ & -0.465 & 0.205 \\
\hline bm3 & -0.223 & 0.154 & bf3 & -0.942 & 0.112 & $\delta \mathrm{f} 2$ & 0.275 & 0.166 \\
\hline bm 4 & -0.209 & 0.157 & bf 4 & -0.638 & 0.113 & $\delta \mathrm{f} 3$ & 0.191 & 0.084 \\
\hline bm5 & -1.866 & 0.200 & bf5 & -0.736 & 0.128 & $\delta f 4$ & 0.069 & 0.046 \\
\hline $\mathrm{cm} 1$ & -0.026 & 0.011 & $\mathrm{cf} 1$ & 0.073 & 0.008 & $\delta \mathrm{f} 5$ & -0.084 & 0.062 \\
\hline $\mathrm{cm} 2$ & -0.144 & 0.019 & $\mathrm{cf} 2$ & -0.237 & 0.015 & & & \\
\hline $\mathrm{cm} 3$ & 0.019 & 0.010 & cf3 & 0.067 & 0.008 & & & \\
\hline $\mathrm{cm} 4$ & 0.015 & 0.010 & $\mathrm{cf} 4$ & 0.044 & 0.008 & & & \\
\hline $\mathrm{cm} 5$ & 0.127 & 0.013 & cf5 & 0.050 & 0.009 & & & \\
\hline em 1 & -0.297 & 0.115 & ef1 & 0.136 & 0.060 & & & \\
\hline $\mathrm{em} 2$ & -0.023 & 0.080 & ef2 & 0.472 & 0.056 & & & \\
\hline em3 & 0.041 & 0.007 & ef3 & 0.006 & 0.004 & & & \\
\hline
\end{tabular}

Notes: Indices running from 1 to 5 denote goods $\mathrm{k}$ in the order: Food Products and Nonalcoholic Beverages, Housing, Housekeeping, Transportation, Entertainment. Indices running from 1 to 3 denote covariate effects in the order: retirement, education, age. 


\section{B. Robustness Checks}

This section provides robustness checks for the results of section 5.1. First, the identical model is estimated using additional data on all singles. Second, the price elasticity parameters $\psi_{j}^{k}\left(\mathbf{z}_{j}\right)$ are excluded from couples' budget share equations.

\section{B1 Estimates Based on Data for Widows, Widowers, Singles and Couples}

Table 9 shows the estimates of the sharing rule and scale economy parameters for an alternative, extended data set using information on singles in addition to widows, widowers and couples. This adds 528 observations to the data, but makes assumption 2 less credible because preferences over goods are assumed to be equal for singles and married individuals. That is, we use data on single women (men) to identify preferences of wives (husbands). ${ }^{22}$

Table 9: Estimates Based on Data for Widows, Widowers, Singles, and Couples

\begin{tabular}{lccc}
\hline & $\begin{array}{c}\text { Sharing rule } \\
\eta(\mathbf{z}) \\
\text { Estimate }\end{array}$ & $\begin{array}{c}\text { Wife scale economy } \\
\ln D_{f}\left(\mathbf{z}_{f}\right) \\
\text { Estimate }\end{array}$ & $\begin{array}{c}\text { Husband scale economy } \\
\ln D_{m}\left(\mathbf{z}_{m}\right) \\
\text { Estimate }\end{array}$ \\
\hline Intercept & $0.403^{* * *}$ & -0.038 & $-0.413^{* * *}$ \\
& $(0.061)$ & $(0.125)$ & $(0.161)$ \\
Wife earns more & 0.022 & & \\
Wife retired & $(0.020)$ & & \\
& -0.008 & -0.055 & $-0.302^{* * *}$ \\
Husband retired & $(0.011)$ & $(0.077)$ & $(0.092)$ \\
& -0.025 & & \\
Education wife & $(0.024)$ & -0.003 & -0.027 \\
& 0.023 & $(0.101)$ & $(0.062)$ \\
Education husband & $(0.022)$ & & \\
& -0.003 & & 0.002 \\
Age wife & $(0.011)$ & -0.009 & $(0.005)$ \\
\hline Age husband & -0.001 & $(0.006)$ & \\
& $(0.001)$ & & \\
\hline
\end{tabular}

Notes: Number of observations: 4810. Number of parameters in the model: 92 . Significance levels: ${ }^{*} 10 \%,{ }^{* *} 5 \%,{ }^{* * *} 1 \%$. Standard error in parentheses.

22 Widows and widowers possibly provide a better comparison as they were living in couples before widowhood. 
The intercept of the female resource share is estimated to be somewhat lower (40.3\%) compared to the baseline model (46.2\%) of section 5.1. This is, however, no significant difference since the $95 \%$ confidence intervals of both estimates overlap. The age variables, which were estimated to increase the share of the husband, turn out to be insignificant. Similar to the main model, retirement status and education are insignificant for the sharing rule. Economies of scale for husbands are estimated to be larger than reported in section 5.1, while those for wives are smaller. The returns to scale are, however, not very precisely estimated; standard errors are similar to the baseline model and $95 \%$ confidence intervals overlap for most of the coefficients. As in section 5.1, retirement is estimated to increase scale economies which indicates that opportunities for joint consumption rise when wife and husband drop out of the labor force.

\section{B2 The Model without Price Elasticity Parameters}

The LP model involves estimation of many parameters. A reduction in the number of coefficients, proposed by Bütikofer, Lewbel, and Seitz (2011), is to omit $\psi_{j}^{k}\left(\mathbf{z}_{j}\right)$, the parameters capturing the elasticities of $D_{j}\left(\mathbf{z}_{j}\right)$ with respect to prices of goods $k$. For the present paper, this approach reduces the number of parameters from 92 to 82 and potentially increases efficiency. There are less parameters because the budget share equations for couples simplify to equation (13):

$$
\begin{aligned}
\omega_{h}^{k} & =\eta(\mathbf{z})\left[\begin{array}{l}
a_{f}^{k 0}+\mathbf{a}_{f}^{k \prime} \mathbf{z}_{f}+\left(x-\ln I_{f}(\mathbf{z})-\mathbf{e}_{f}^{\prime} \mathbf{z}_{f}\right) b_{f}^{k} \\
+\left(x-\ln I_{f}(\mathbf{z})-\mathbf{e}_{f}^{\prime} \mathbf{z}_{f}\right)^{2} c_{f}^{k}
\end{array}\right] \\
& +(1-\eta(\mathbf{z}))\left[\begin{array}{l}
a_{m}^{k 0}+\mathbf{a}_{m}^{k \prime} \mathbf{z}_{m}+\left(x-\ln I_{m}(\mathbf{z})-\mathbf{e}_{m}^{\prime} \mathbf{z}_{m}\right) b_{m}^{k} \\
+\left(x-\ln I_{m}(\mathbf{z})-\mathbf{e}_{m}^{\prime} \mathbf{z}_{m}\right)^{2} c_{m}^{k}
\end{array}\right] \\
& +\varepsilon_{b}^{k} .
\end{aligned}
$$

The results for this model are shown in Table 10. For the reference group, the restricted model yields a female resource share of 0.355 . This estimate is 10.7 percentage points lower than the coefficient found when price elasticities are included. While scale economies of husbands are similar to the baseline model, the estimate for wives is considerably different. Women in couples are now estimated to face $93.1 \%$ of the cost, which is clearly more than the $80.7 \%$ that were found in the unrestricted model. Moreover, the impact of covariates on resource shares and scale economies is not stable, e.g., the previously positive effect of higher income of the wife on resource shares turns insignificant. 
The restriction $\psi_{j}^{k}\left(\mathbf{z}_{j}\right)=0$, i.e., price elasticities of $D_{j}\left(\mathbf{z}_{j}\right)$ are zero, is found to have more impact on the results than including additional data on all singles in the unrestricted model. In addition, the restriction did not make the estimation much more efficient. In line with these findings, the joint null hypothesis of price elasticities equal to zero in the main model (section 5.1) is rejected on the $1 \%$ level.

Table 10: Estimates for the Restricted Model without Price Elasticity Parameters

\begin{tabular}{lccc}
\hline & $\begin{array}{c}\text { Sharing rule } \\
\eta(\mathbf{z}) \\
\text { Estimate }\end{array}$ & $\begin{array}{c}\text { Wife scale economy } \\
\ln D_{f}\left(\mathbf{z}_{f}\right) \\
\text { Estimate }\end{array}$ & $\begin{array}{c}\text { Husband scale economy } \\
\ln D_{m}\left(\mathbf{z}_{m}\right) \\
\text { Estimate }\end{array}$ \\
\hline Intercept & $0.355^{* * *}$ & -0.072 & $-0.231^{* *}$ \\
& $(0.045)$ & $(0.099)$ & $(0.116)$ \\
Wife earns more & -0.008 & & \\
Wife retired & $(0.019)$ & & \\
& -0.004 & -0.068 & -0.156 \\
Husband retired & $(0.017)$ & $(0.071)$ & $(0.099)$ \\
& 0.025 & & \\
Education wife & $(0.021)$ & $-0.176^{* *}$ & 0.106 \\
& 0.039 & $(0.088)$ & $(0.077)$ \\
Education husband & $(0.026)$ & & \\
& $-0.044^{*}$ & & $0.029^{* * *}$ \\
Age wife & $(0.024)$ & 0.001 & $(0.007)$ \\
\hline Age husband & -0.001 & $(0.005)$ & \\
& $(0.001)$ & & \\
\hline
\end{tabular}

Notes: Number of observations: 4282 . Number of parameters in the model: 82 . Significance levels: * $10 \%,{ }^{* *} 5 \%,{ }^{* * *} 1 \%$. Standard error in parentheses.

\section{References}

Apps, Patricia Frances, and Ray Rees (1997), "Collective Labor Supply and Household Production", Journal of Political Economy, 105(1), pp. 178-190.

Banks, James, Richard Blundell, and Arthur Lewbel (1997), "Quadratic Engel Curves and Consumer Demand", The Review of Economics and Statistics, 79(4), pp. 527-539. 
Bargain, Olivier, and Olivier Donni (2012), "The Measurement of Child Costs: A Rothbarth-type Method Consistent with Scale Economies and Parents' Bargaining", European Economic Review, 56(4), pp. 792-813.

Bourguignon, François, Martin Browning, Pierre-André Chiappori, and Valérie LeChene (1993), "Intra Household Allocation of Consumption: A model and Some Evidence from French Data", Annals of Economics and Statistics / Annales d'Économie et de Statistique, (29), pp. 137-156.

Browning, Martin, François Bourguignon, Pierre-André Chiappori, and Valérie Lechene (1994), "Income and Outcomes: A Structural Model of Intrahousehold Allocation", Journal of Political Economy, 102(6), pp. 1067-1096.

Browning, Martin, and Pierre-André Chiappori (1998), "Efficient IntraHousehold Allocations: A General Characterization and Empirical Tests", Econometrica, 66(6), pp. 1241-1278.

Browning, Martin, Pierre-André Chiappori, and Arthur Lewbel (2013), "Estimating Consumption Economies of Scale, Adult Equivalence Scales, and Household Bargaining Power", Review of Economic Studies, 80(4), pp. 1267-1303.

Bütikofer, Aline, and Michael Gerfin (2017), "The Economies of Scale of Living Together and how They Are Shared: Estimates Based on a Collective Household Model”, Review of Economics of the Household, 15(2), pp. 433-453.

Bütikofer, Aline, Arthur Lewbel, and Shannon Seitz (2011), "Health and Retirement Effects in a Collective Consumption Model of Older Households", Boston College Working Papers in Economics.

Cherchye, Laurens, Bram De Rock, Arthur Lewbel, and Frederic Vermeulen (2015), "Sharing Rule Identification for General Collective Consumption Models", Econometrica, 83(5), pp. 2001-2041.

Cherchye, Laurens, Bram De Rock, and Frederic Vermeulen (2011), "The Revealed Preference Approach to Collective Consumption Behaviour: Testing and Sharing Rule Recovery", The Review of Economic Studies, 78(1), pp. 176-198.

Cherchye, Laurens, Bram De Rock, and Frederic Vermeulen (2012), "Economic Well-Being and Poverty among the Elderly: An Analysis Based on a Collective Consumption Model", European Economic Review, 56(6), pp. 985-1000.

Cherchye, Laurens, Thomas Demuynck, and Bram De Rock (2011), "Revealed Preference Analysis of Non-Cooperative Household Consumption", The Economic Journal, 121(555), pp. 1073-1096. 
Chiappori, Pierre-André (1988), "Nash-Bargained Households Decisions: A Comment", International Economic Review, 29(4), pp.791-796.

Chiappori, Pierre-André (1992), "Collective Labor Supply and Welfare", Journal of Political Economy, 100(3), pp. 437-467.

Dunbar, Geoffrey, Arthur Lew bel, and Krishna Pendakur (2013), "Children's Resources in Collective Households: Identification, Estimation, and an Application to Child Poverty in Malawi", American Economic Review, 103(1), pp. 438-471.

Lewbel, Arthur, and Krishna Pendakur (2008), "Estimation of Collective Household Models with Engel Curves", Journal of Econometrics, 147(2), pp. 350-358.

Lise, Jeremy, and Shannon Seitz (2011), "Consumption Inequality and Intrahousehold Allocations", The Review of Economic Studies, 78(1), pp. 328-355.

Lundberg, Shelly J., Robert A. Pollak, and Terence J. Wales (1997), "Do Husbands and Wives Pool Their Resources? Evidence from the United Kingdom Child Benefit", The Journal of Human Resources, 32(3), pp. 463-480.

Manser, Marilyn, and Murray Brown (1980), "Marriage and Household Decision-Making: A Bargaining Analysis", International Economic Review, 21(1), pp. 31-44.

McElroy, Marjorie B., and Mary Jean Horney (1981), "Nash-Bargained Household Decisions: Toward a Generalization of the Theory of Demand", International Economic Review, 22(2), pp.333-349.

Michaud, Pierre-Carl, and Frederic Vermeulen (2011), "A Collective Labor Supply Model with Complementarities in Leisure: Identification and Estimation by Means of Panel Data", Labour Economics, 18(2), pp. 159-167.

Schultz, T. Paul (1990), "Testing the Neoclassical Model of Family Labor Supply and Fertility", The Journal of Human Resources, 25(4), pp. 599-634.

Thomas, Duncan (1990), "Intra-Household Resource Allocation: An Inferential Approach", The Journal of Human Resources, 25(4), pp. 635-664. 